\title{
Periodontal ligament and gingival fibroblasts participate in the production of TGF- $\beta$, interleukin (IL)-8 and IL-10
}

\section{Ana Carolina de Faria Morandini(a) \\ Carla Renata Sipert ${ }^{(a)}$ \\ Erivan Schnaider Ramos-Junior ${ }^{(b)}$ \\ Daniel Thomas Brozoski(a) \\ Carlos Ferreira Santos ${ }^{(a)}$}

(a) Department of Biological Sciences, Bauru School of Dentistry, University of São Paulo, Bauru, SP, Brazil.

(b) Carlos Chagas Filho Institute of Biophysics, Institute of Biomedical Sciences, Federal University of Rio de Janeiro, Rio de Janeiro, RJ, Brazil.

\section{Corresponding author:}

Carlos Ferreira Santos

Alameda Octávio Pinheiro Brisolla, 9-75

Bauru - SP - Brazil

CEP: 17012-901

E-mail:cebola@usp.br

Received for publication on Oct 27, 2010 Accepted for publication on Jan 16, 2011

\begin{abstract}
The aim of this study was to quantify and compare the production of transforming growth factor beta (TGF- $\beta$ ), interleukin (IL)- 8 and IL-10 by human cultured periodontal ligament and gingival fibroblasts both obtained from the same donors challenged with lipopolysaccharide (LPS) from Porphyromonas gingivalis. Fibroblasts were exposed to $0.1-10 \mu \mathrm{g} / \mathrm{mL}$ of LPS from $P$. gingivalis and after $24 \mathrm{~h}$ the supernatants were collected and analyzed by enzyme-linked immunosorbent assay (ELISA). TGF- $\beta$ protein production was upregulated in a concentration-dependent manner, mainly in gingival fibroblasts, which was statistically significant when challenged by $10 \mu \mathrm{g} / \mathrm{mL}$ LPS. Additionally, at this concentration, gingival fibroblasts had almost a two-fold increase in the amount of TGF- $\beta$ when compared to periodontal ligament fibroblasts. Both periodontal ligament and gingival fibroblasts showed an increase in IL-8 production when challenged with $1 \mu \mathrm{g} / \mathrm{mL}$ and $10 \mu \mathrm{g} / \mathrm{mL}$ LPS. IL-10 production remained unaffected when challenged by any of the LPS concentrations tested in either periodontal ligament or gingival fibroblasts. Our results demonstrate that periodontal ligament and gingival fibroblasts when challenged by LPS from $P$. gingivalis with $24 \mathrm{~h}$ may play a critical role in producing TGF- $\beta$ and IL- 8 but not IL-10.
\end{abstract}

Descriptors: Periodontitis; Fibroblasts; Cytokines; Porphyromonas gingivalis.

\section{Introduction}

Periodontitis is a complex chronic infectious disease that leads to the destruction of the tooth-supporting tissues, including alveolar bone, and that leads to tooth loss. ${ }^{1}$ The presence of periodontopathogens, such as Porphyromonas gingivalis, is considered the major etiologic agent in periodontitis. ${ }^{2} P$. gingivalis is a Gram-negative anaerobic bacterium that possesses a number of virulence factors, including lipopolysaccharides (LPS). ${ }^{3}$ LPS acts as a potent stimulus to a variety of host cells, which subsequently results in the expression of inflammatory cytokines leading to the development and progression of the related host immune response in periodontal diseases. ${ }^{4}$

Numerous studies have demonstrated that cytokine networks play an important role in the initiation and progression of periodontal disease. ${ }^{5}$ Interleukin (IL)- 8 is a chemokine produced by a variety of tissues, and it is a potent inducer of neutrophil chemotaxis and activation. ${ }^{6}$ The stimu- 
lation of human gingival fibroblasts with highly purified $P$. gingivalis LPS led to mRNA expression of IL-8. ${ }^{7}$ In contrast, IL-10, an anti-inflammatory cytokine, plays a major role in suppressing immune and inflammatory responses. ${ }^{8}$ Indeed, IL-10 presents a protective role toward tissue destruction, inhibiting both matrix metalloproteinases (MMPs) and receptor activator for nuclear factor-kB (RANK) systems, which leads to the differentiation and activation of osteoclasts. ${ }^{9}$ In inflamed gingival tissues, IL-10 potentiates local autoimmune responses characterized by increasing the number of anti-collagen secreting cells. ${ }^{10}$

Interestingly, transforming growth factor beta (TGF- $\beta$ ) is a highly conserved and ubiquitously expressed cytokine, and most cells express members of the TGF- $\beta$ receptor family. ${ }^{11}$ During the progression of periodontal inflammation, periodontal ligament and gingival fibroblasts secrete high levels of cytokines and chemokines. ${ }^{12}$ In one previous study, it was demonstrated that human gingival and periodontal ligament fibroblasts distinctly responded to a time-course $P$. gingivalis LPS challenge with the production of macrophage inflammatory protein$1 \alpha$, stromal derived factor- 1 and IL- $6 .{ }^{13}$ The present study further investigates the interrelationship between both subtypes of fibroblasts collected from the same donors in the production of TGF- $\beta$, IL- 8 and IL-10 when challenged with LPS.

\section{Materials and Methods Cell culture}

Fibroblasts were obtained as previously described. ${ }^{13}$ Briefly, human periodontal ligament fibroblasts were extracted from three healthy donors. Donors had given written informed consent, and the study was approved by the Ethics Committee of the Bauru School of Dentistry, University of São Paulo. Concurrently, gingival biopsies from the same donors were obtained. Tissue fragments of periodontal ligament and gingiva were individually plated in 100 X $10 \mathrm{~mm}$ Petri dishes and covered with $5 \mathrm{~mL}$ of Dulbecco's modified Eagle's medium (DMEM; Invitrogen Life Technologies, Carlsbad, CA, USA) supplemented with $10 \%$ fetal bovine serum (FBS; Cultilab, Campinas, SP, Brazil) and antibiotics (600 $\mu \mathrm{l} /$
$\mathrm{mL}$ penicillin, $300 \mu \mathrm{l} / \mathrm{mL}$ gentamicin sulfate, $100 \mu \mathrm{l} /$ $\mathrm{mL}$ amphotericin B; Invitrogen Life Technologies, Carlsbad, CA, USA). After minced, the explants were placed in $25-\mathrm{cm}^{2}$ flasks and incubated at $37^{\circ} \mathrm{C}$ in a humidified atmosphere of $5 \% \mathrm{CO}_{2}$. Medium change (DMEM 10\% FBS) was performed every second day. Cells were used at the fourth passage.

\section{LPS challenge}

Fibroblasts were seeded at a density of $5 \times 10^{4}$ cells/well and incubated in the absence (controls) or presence of $0.1,1$ or $10 \mu \mathrm{g} / \mathrm{mL}$ of LPS from P. gingivalis (InvivoGen, San Diego, CA, USA) in duplicate as previously described. ${ }^{14}$ After $24 \mathrm{~h}$, the supernatant was collected and analyzed by enzyme-linked immunosorbent assay (ELISA).

\section{ELISA}

ELISAs, to determine the protein levels of TGF- $\beta$, IL- 8 and IL-10, were performed using the Ready-Set-Go! ELISA kits (eBioscience, San Diego, CA, USA), according to the manufacturer's protocol. Dilutions were prepared in dilution buffer. Briefly, 96-well plates were coated with antihuman TGF- $\beta$, IL- 8 or IL-10 monoclonal antibodies. After blocking with the assay solution for $2 \mathrm{~h}$ to avoid non-specific binding, $100 \mu \mathrm{L}$ of standard TGF- $\beta$, IL- 8 or IL-10 or culture supernatants were added. The cytokines were detected by horseradish peroxidase-labeled monoclonal antibody to each target after $100 \mu \mathrm{L}$ of anti-human biotinylated antibodies were placed in each well and incubated for $2 \mathrm{~h}$ at $21^{\circ} \mathrm{C}$. The microplate was washed to remove unbound enzyme-labeled antibodies. The amount of horseradish peroxidase bound to each well was determined by the addition of substrate solution. The reaction was stopped by the addition of sulfuric acid and the plates were read at $450 \mathrm{~nm}$ (ELISA microplate reader, Bio-Rad, Hercules, CA, USA). The concentrations of each target were determined by interpolation from a standard curve and presented as $\mathrm{pg} / \mathrm{mL}$ ( \pm one standard error of the mean).

\section{Statistical analysis}

Statistical analysis was performed with GraphPad Prism 5.0 software (GraphPad Prism 5.0, 
GraphPad Software, San Diego, CA, USA). Data were compared using a one-way analysis of variance and differences were identified using the Tukey's test, with significance set at $p<0.05$.

\section{Results}

\section{TGF- $\beta$ is distinctly produced by human gingival and periodontal ligament fibroblasts}

When challenged with P.gingivalis LPS at a concentration of $10 \mu \mathrm{g} / \mathrm{mL}$, gingival fibroblasts produced a significantly increased level of TGF- $\beta$ when compared to control (Figure 1). As shown in Figure 1 , periodontal ligament fibroblasts treated with any concentration of LPS did not exhibit statistically significant differences when compared among any other LPS concentration or medium. At the highest LPS concentration tested, the TGF- $\beta$ amounts detected in gingival fibroblasts were almost two-fold $(p<0.05)$ increased in comparison to the protein levels for periodontal ligament cells.

\section{IL-8 levels in gingival and periodontal ligament fibroblasts were significant above $1.0 \mu \mathrm{g} / \mathrm{mL}$}

There was no difference in IL-8 production at the lowest concentration of LPS tested $(0.1 \mu \mathrm{g} / \mathrm{mL})$ (Figure 2). However, when $1 \mu \mathrm{g} / \mathrm{mL}$ of $P$. gingivalis LPS was used, the amount of IL-8 increased signifi-

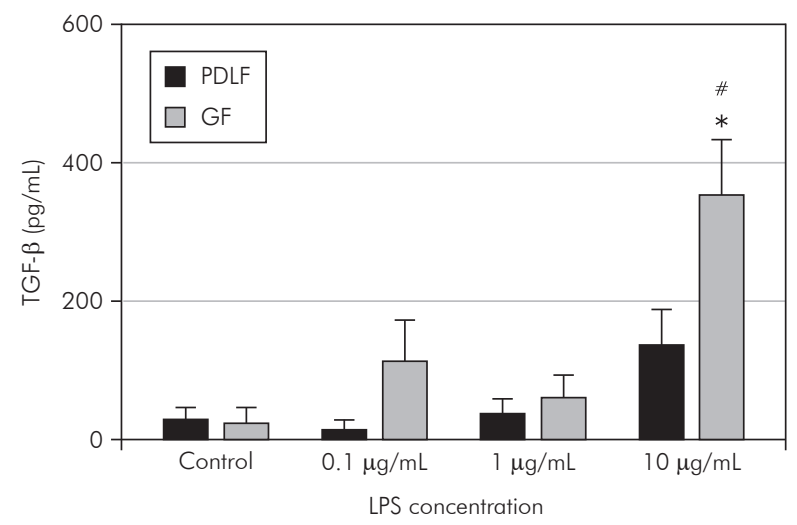

Figure 1 - TGF- $\beta$ production by human cultured periodontal ligament and gingival fibroblasts challenged with LPS from $P$. gingivalis. ELISA was performed for the quantification of the cytokines on the cell culture supernatants. ${ }^{*} p<0.05$ between the same cell subtype. ${ }^{*} p<0.05$ between different subtypes of fibroblasts (gingival $X$ periodontal ligament). cantly $(p<0.05)$ (Figure 2). Differences between the two subtypes of fibroblasts at any particular concentration were statistically undetectable regarding IL-8 production (Figure 2).

\section{IL-10 production is unaffected by LPS concentration in either fibroblast subtypes}

In all concentrations of $P$. gingivalis LPS tested $(0 \mu \mathrm{g} / \mathrm{mL}$ to $10 \mu \mathrm{g} / \mathrm{mL})$, periodontal ligament and gingival fibroblasts showed no changes in the amount of IL-10 when compared to control (Figure 3). Additionally, there were no differences observed between them at each of the LPS concentrations tested in this study (Figure 3).

\section{Discussion}

This study investigated the in vitro responses of periodontal ligament and gingival fibroblasts provided by the same donors in response to a wellknown virulence factor from $P$. gingivalis, LPS, by quantifying important cytokines represented by TGF- $\beta$, IL- 8 and IL- 10 . These cytokines along with others play a vital role in inflammatory disease such as periodontitis. ${ }^{15}$ An earlier work ${ }^{16}$ showed that the magnitude of the responses of gingival and periodontal ligament fibroblasts to $P$. gingivalis varies markedly between individuals. Particularly, it is possible that heterogeneity in the responses is caused by the host genetic background of the cells,

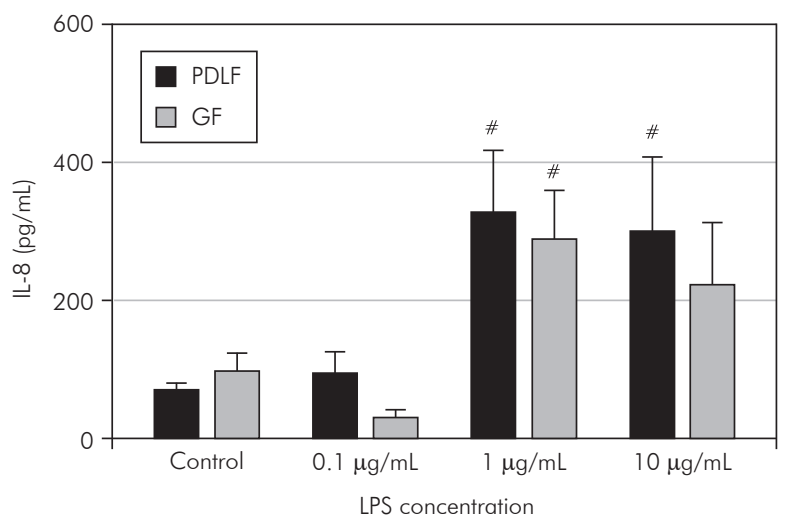

Figure 2 - IL-8 production by human cultured periodontal ligament and gingival fibroblasts challenged with LPS from $P$. gingivalis. ELISA was performed for the quantification of the cytokines on the cell culture supernatants. ${ }^{*} p<0.05$ in comparison with the other concentrations of LPS in the same subtype. 


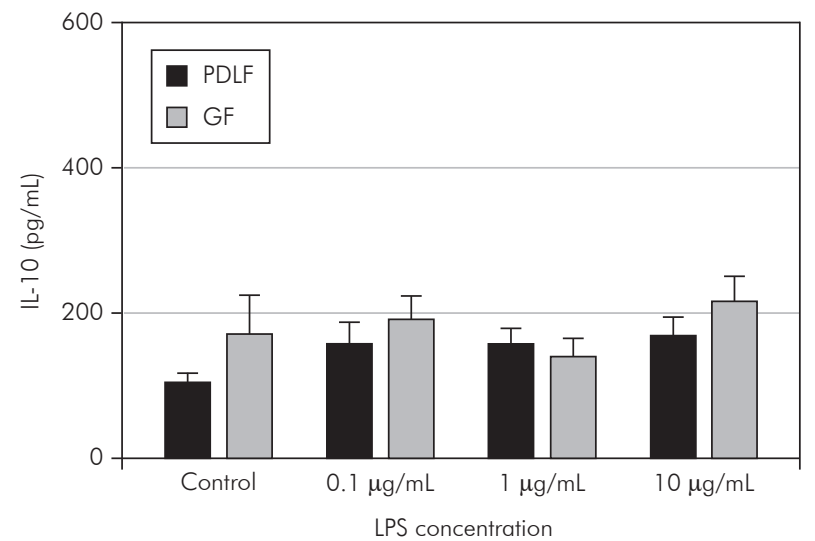

Figure 3 - IL-10 production by human cultured periodontal ligament and gingival fibroblasts challenged with LPS from $P$. gingivalis. ELISA was performed for the quantification of the cytokines on the cell culture supernatant.

and thus periodontal ligament fibroblasts and gingival fibroblasts were collected and compared from the same donors.

Previously, other investigators have shown that viable $P$. gingivalis induces cytokine responses in monocytes and macrophages that are significantly different from those induced by purified LPS or by the major fimbrial protein FimA. ${ }^{17}$ For example, viable $P$. gingivalis induced increased IL- 6 and IL- 8 gene-expression when compared to dead $P$. gingivalis in periodontal fibroblasts. ${ }^{16}$ The amount of TGF- $\beta$ production was the only mediator that significantly differed between periodontal ligament and gingival fibroblasts, and this difference was observed at the highest concentration of $P$. gingivalis LPS used. This result may indicate a more activated state for gingival fibroblasts over periodontal ligament cells, given that gingival fibroblasts are more likely to encounter oral pathogens. TGF- $\beta$ is credited for promoting wound fibroblasts to differentiation at sites of inflammation and repair. ${ }^{18}$ The unique pattern of production for cytokines by gingival fibroblasts observed could be due to its more pronounced repair characteristic. In a previous study, we demonstrated this distinct ability of cytokine production in these two subtypes of fibroblasts under the same challenge. ${ }^{13}$ Since these fibroblasts have different functional characteristics, it may be reasonable to assume that their role in the inflammatory process in periodontitis may also differ. An up-regulation in IL-6 levels was previously shown, ${ }^{13}$ which had a strong positive correlation with the levels of TGF- $\beta$ reported in this work.

Taking this into account, studies have shown that the presence of IL- 6 , in addition to TGF- $\beta$, skews the commitment towards a population of $\mathrm{CD}^{+} \mathrm{T}$ helper cells discrete from Th1 and Th2, known as $\mathrm{T}$ helper type 17 cells (Th17). ${ }^{19,20}$ Th17 cells are considered an independent $\mathrm{T}$ helper cell lineage in human and mouse which can potentially induce tissue inflammation and has been associated with the pathogenesis of many experimental autoimmune diseases and human inflammatory conditions. Moreover, it was found that TGF- $\beta$ together with IL-6 induces massive amounts of IL-17 from naïve $\mathrm{T}$ cells and consequently these two cytokines together can differentiate Th 17 lineage. Interestingly, two cytokines with opposing effects have to cooperate to induce the differentiation of Th17 cells. ${ }^{21}$ Also, the presence of Th17 cells in the chronic inflammation in human periodontal disease was demonstrated as well as IL-17 expression in the alveolar bone of patients with chronic periodontitis. ${ }^{22}$ Studies linking apoptotic cell recognition and clearance report an induction of TGF- $\beta$ secretion, resulting in accelerated resolution of inflammation. ${ }^{23}$ In an independent study, ${ }^{18}$ TGF- $\beta$ was found to be produced by LPS-treated human gingival fibroblasts and this level of TGF- $\beta$ was unable to decrease IL- 8 production, corroborating our findings.

In this study, $1 \mu \mathrm{g} / \mathrm{mL}$ of $P$. gingivalis LPS caused the levels of IL-8 production to increase significantly $(p<0.05)$ for both gingival and periodontal ligament fibroblasts. Even though the concentration of P. gingivalis LPS was 10 times greater, IL- 8 release was maintained in both fibroblast subtypes. The fact that at least $1 \mu \mathrm{g} / \mathrm{mL}$ of $P$. gingivalis LPS caused IL-8 to significantly increase compared to control $(p<0.05)$ is curious. One could speculate that this may be at or close to the minimum concentration of LPS able to induce these cells to some pro-inflammatory reaction. It is still important to emphasize that IL-8 is an extensively studied chemokine related to neutrophil recruitment, ${ }^{24}$ and it is essential in the first line of defense.

It has been reported that IL-10 mediates the 
control of periodontal disease progression. ${ }^{10}$ Controversy still exists about IL-10's expression profile in periodontal health and disease. It has been shown that IL-10 levels in gingival crevicular fluid were only detected in samples from periodontal patients, ${ }^{25}$ and that T-cell lines derived from adult periodontitis subjects but not those from gingivitis subjects could produce IL-10. ${ }^{26}$ In contrast, IL-10 expression in periodontitis lesions was less than that in healthy gingival tissue. ${ }^{27}$ In the current study, curiously, no differences were found in IL-10 levels between fibroblasts with or without a P. gingivalis LPS challenge. In essence, this could be a consequence of an in vitro experimental model, which in some way might restrict the results, without considering the micro-environmental factors usually involved in vivo. Recent data has shown that in the early phases of inflammation, IL-10 expression was coordinated with other genes expression that had potent pro-inflammatory and chemoattractant properties. Only during later stages, the function of IL-10 did converge into a congruent attempt to limit the tissue damage by dampening the inflammatory process. ${ }^{28}$ This finding may indirectly explain the diversity of the IL-10 expression pattern observed in periodontal health and disease. A recent study used gingival fibroblasts treated with $P$. gingivalis LPS for $48 \mathrm{~h}$ and reported increased expression of IL-10 when

\section{References}

1. Feng Z, Weinberg A. Role of bacteria in health and disease of periodontal tissues. Periodontol 2000. 2006 Feb;40(1):50-76.

2. van Winkelhoff AJ, Loos BG, van der Reijden WA, van der Velden U. Porphyromonas gingivalis, Bacteroides forsythus and other putative periodontal pathogens in subjects with and without periodontal destruction. J Clin Periodontol. 2002 Nov;29(11):1023-8.

3. O'Brien-Simpson NM, Veith PD, Dashper SG, Reynolds EC. Antigens of bacteria associated with periodontitis. Periodontol 2000. 2004 Jun;35:101-34.

4. Ren L, Leung WK, Darveau RP, Jin L. The expression profile of lipopolysaccharide-binding protein, membrane-bound CD14, and toll-like receptors 2 and 4 in chronic periodontitis. J Periodontol. 2005 Nov;76(11):1950-9.

5. Salvi GE, Lang NP. Host response modulation in the management of periodontal diseases. J Clin Periodontol. 2005 Oct;32 Suppl 6:108-29. compared to the untreated control. ${ }^{29}$ It is possible that the $48 \mathrm{~h}$ time period between the $P$. gingivalis LPS treatment start until the detection of IL-10 levels in the previous study may have allowed gingival fibroblasts to more fully mature than $24 \mathrm{~h}$. Our results demonstrated that human cultured periodontal ligament and gingival fibroblasts significantly increased levels of IL-8 when challenged with $P$. gingivalis LPS and that gingival fibroblasts significantly increased levels of TGF- $\beta$. Additionally, periodontal fibroblasts produced active TGF- $\beta$, but not at enough quantities to decrease IL- 8 production. On the other hand, the strong positive correlation between IL- 6 and TGF- $\beta$ calls one's attention to the possible association of gingival fibroblasts with the maintenance of a Th17 profile at the periodontal inflammatory microenvironment.

\section{Conclusions}

Taken together, these findings suggest that human periodontal ligament and gingival fibroblasts may act as immune-responsive cells, but in a differential manner. Regarding IL-10, no differences were detected in any of the LPS concentrations. Both subtypes of fibroblasts can increase IL-8 levels but only gingival fibroblasts significantly increase TGF- $\beta$ levels when challenged with P. gingivalis LPS for $24 \mathrm{~h}$.

6. Baggiolini M, Dewald B, Moser B. Interleukin-8 and related chemotactic cytokines-- CXC and CC chemokines. In: Dixon FJ, editor. Advances in immunology. New York: Academic Press; 1993. p. 97-179.

7. Mahanonda R, Sa-Ard-Iam N, Montreekachon P, Pimkhaokham A, Yongvanichit K, Fukuda MM, et al. IL-8 and IDO expression by human gingival fibroblasts via TLRs. J Immunol. 2007 Jan 15;178(2):1151-7.

8. Al-Rasheed A, Scheerens H, Rennick DM, Fletcher HM, Tatakis DN. Accelerated alveolar bone loss in mice lacking interleukin-10. J Dent Res. 2003 Aug;82(8):632-5.

9. Garlet GP, Cardoso CR, Silva TA, Ferreira BR, Avila-Campos $\mathrm{MJ}$, Cunha FQ, et al. Cytokine pattern determines the progression of experimental periodontal disease induced by Actinobacillus actinomycetemcomitans through the modulation of MMPs, RANKL, and their physiological inhibitors. Oral Microbiol Immunol. 2006 Feb;21(1):12-20. 
10. Gemmell E, Marshall RI, Seymour GJ. Cytokines and prostaglandins in immune homeostasis and tissue destruction in periodontal disease. Periodontol 2000. 1997 Jun;14(1):11243.

11. Chen W, Wahl SM. TGF-beta: receptors, signaling pathways and autoimmunity. In: Altman A, editor. Signal transduction pathways in autoimmunity. Basel: Karger; 2002. p. 62-91.

12. Boch JA, Wara-aswapati N, Auron PE. Interleukin 1 signal transduction--current concepts and relevance to periodontitis. J Dent Res. 2001 Feb;80(2):400-7.

13. Morandini AC, Sipert CR, Gasparoto TH, Greghi SL, Passanezi E, Rezende ML, et al. Differential production of macrophage inflammatory protein-1alpha, stromal-derived factor-1, and IL- 6 by human cultured periodontal ligament and gingival fibroblasts challenged with lipopolysaccharide from P. gingivalis. J Periodontol. 2010 Feb;81(2):310-7.

14. Hosokawa Y, Hosokawa I, Ozaki K, Nakae H, Murakami K, Miyake Y, et al. CXCL12 and CXCR4 expression by human gingival fibroblasts in periodontal disease. Clin Exp Immunol. 2005 Sep;141(3):467-74.

15. Lerner UH. Inflammation-induced bone remodeling in periodontal disease and the influence of post-menopausal osteoporosis. J Dent Res. 2006 Jul;85(7):596-607.

16. Scheres N, Laine ML, de Vries TJ, Everts V, van Winkelhoff AJ. Gingival and periodontal ligament fibroblasts differ in their inflammatory response to viable Porphyromonas gingivalis. J Periodontal Res. 2010 Apr; 45(2):262-70.

17. Zhou Q, Amar S. Identification of signaling pathways in macrophage exposed to Porphyromonas gingivalis or to its purified cell wall components. J Immunol. 2007 Dec 1;179(11):7777-90.

18. Rahimi F, Hsu K, Endoh Y, Geczy CL. FGF-2, IL-1beta and TGF-beta regulate fibroblast expression of S100A8. FEBS J. 2005 Jun;272(11):2811-27.

19. Bettelli E, Carrier Y, Gao W, Korn T, Strom TB, Oukka M, et al. Reciprocal developmental pathways for the generation of pathogenic effector TH17 and regulatory T cells. Nature. 2006 May 11;441(7090):235-8.
20. Mangan PR, Harrington LE, O'Quinn DB, Helms WS, Bullard DC, Elson CO, et al. Transforming growth factor-beta induces development of the $\mathrm{T}(\mathrm{H}) 17$ lineage. Nature. 2006 May 11;441(7090):231-4.

21. Korn T, Bettelli E, Oukka M, Kuchroo VK. IL-17 and Th17 Cells. Annu Rev Immunol. 2009 Apr;27(1):485-517.

22. Cardoso CR, Garlet GP, Crippa GE, Rosa AL, Junior WM, Rossi MA, et al. Evidence of the presence of T helper type 17 cells in chronic lesions of human periodontal disease. Oral Microbiol Immunol. 2009 Feb;24(1):1-6.

23. Xiao YQ, Freire-de-Lima CG, Schiemann WP, Bratton DL, Vandivier RW, Henson PM. Transcriptional and translational regulation of TGF-beta production in response to apoptotic cells. J Immunol. 2008 Sep 1;181(5):3575-85.

24. Seitz M, Dewald B, Gerber N, Baggiolini M. Enhanced production of neutrophil-activating peptide-1/interleukin-8 in rheumatoid arthritis. J Clin Invest. 1991 Feb;87(2):463-9.

25. Gamonal J, Acevedo A, Bascones A, Jorge O, Silva A. Levels of interleukin- 1 beta, -8 , and -10 and RANTES in gingival crevicular fluid and cell populations in adult periodontitis patients and the effect of periodontal treatment. J Periodontol. 2000 Oct;71(10):1535-45.

26. Gemmell E, Kjeldsen M, Yamazaki K, Nakajima, Aldred MJ, Seymour. Cytokine profiles of Porphyromonas gingivalis-reactive $\mathrm{T}$ lymphocyte line and clones derived from $P$. gingivalisinfected subjects. Oral Dis. 1995 Sep;1(3):139-46.

27. Yamazaki K, Tabeta K, Nakajima T, Ohsawa Y, Ueki K, Itoh $\mathrm{H}$, et al. Interleukin-10 gene promoter polymorphism in Japanese patients with adult and early-onset periodontitis. J Clin Periodontol. 2001 Sep;28(9):828-32.

28. Mocellin S, Panelli MC, Wang E, Nagorsen D, Marincola FM. The dual role of IL-10. Trends Immunol. 2003 Jan;24(1):3643.

29. Almasri A, Wisithphrom K, Windsor LJ, Olson B. Nicotine and lipopolysaccharide affect cytokine expression from gingival fibroblasts. J Periodontol. 2007 Mar;78(3):533-41. 